\title{
Crystal, molecular and electronic structure of (5S,8aS)-5-methyl-4,6,7,8,8a,9-hexahydrothieno-[3,2-f] indolizinium iodide
}

\author{
Viktor Vrábel $^{a}$, Július Sivýb, Peter Šafařc, Jozefína Žúžiovác \\ ${ }^{a}$ Institute of Analytical Chemistry, Faculty of Chemical and Food Technology, Slovak Technical University, \\ Radlinského 9, SK-812 37 Bratislava, Slovak Republic \\ ${ }^{b}$ Institute of Mathematics and Physics, Faculty of Mechanical Engineering, Slovak University of Technology, \\ Námestie slobody 17, SK-812 31 Bratislava, Slovak Republic \\ 'Institute of Organic Chemistry, Catalysis and Petrochemistry, Faculty of Chemical and Food Technology, \\ Slovak Technical University, Radlinského 9, SK-812 37 Bratislava, Slovak Republic \\ viktor.vrabel@stuba.sk
}

\begin{abstract}
The molecules of the title compound, $\mathrm{C}_{11} \mathrm{H}_{16}$ NS.I, crystallize as single enantiomer with two stereogenic centre, their absolute configuration were confirmed by anomalous dispersion effects in diffraction measurements on the crystals. The conformation of the pyrrolidine ring is close to that of an envelope, with the flap atom N1 displaced by 0.661 (2) A from the plane of the oder remaining four atoms. The central six-membered ring of the indolizine moiety adopt a half-chair conformation with atom C5 displaced by -0.686 (2) $\AA$ from the plane of the oder remaining five atoms. The crystal structure of the title compound is stabilized by $\mathrm{C}-\mathrm{H} \cdots \mathrm{I} \cdots \mathrm{H}-\mathrm{C}$ hydrogen interactions.
\end{abstract}

Keywords: conformation, crystal and electronic structure, hydrogen interactions, indolizine, single-crystal X-ray study.

\section{Introduction}

Indolizidines with different degrees of unsaturation are part of the skeleton of numerous natural compounds found in a large number of plants, animals, bacteria, and fungi. They occupy an important and privileged position in modern organic chemistry, because of their wide spectrum of biological activity. For example, polyhydroxylated indolizidine alkaloids represented by the so popular castanospermine and swainsonine are well known for their ability to function as excellent inhibitors of biologically important pathways. These include the binding and processing of glycoproteins, potent glycosidase inhibitory activities (Melo et al., 2006; Michael, 2003; Lillelund et al., 2002), activity against AIDS virus $\mathrm{HIV}$ and some carcinogenic cells as well as against other important pathologies (Gerber-Lemaire, Juillerat-Jeanneret, 2006; Butters, 2002; Compain, Martin, 2001). More importantly, some hybrids of these structures have shown in numerous cases an increase of glycosidase activities as demonstrated by the Pearson's group and others (Shi et al., 2008; Fujita et al., 2004). Indolizines have also been tested as antimycobacterial agents against mycobacterial tuberculosis (Gundersen, et al., 2003). Many studies demonstrated that indolizine derivatives show biological activity such as antioxidative (Teklu et al., 2005) and antiherpes (Foster et al., 1995). The other well known pharmacological applications associated with this ring compounds are well documented in the literature (Couture et al., 2000; Jorgensen et al., 2000). Based on these facts and in continuation of our interest in developing simple and efficient route for the synthesis of novel indolizine derivatives, we report here the synthesis, molecular and crystal structure of the title compound (Fig. 1), which crystallizes in the noncentrosymetric orthorhombic space group $P 2_{1} 2_{1} 2_{1}$ with one crystallographic independent molecule in asymmetric unit.

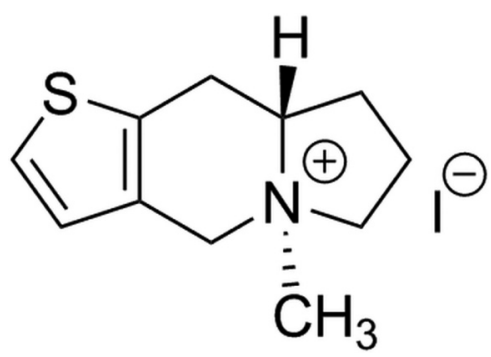

Fig. 1. The molecular structure of the title compound.

\section{Experimental}

The title compound ( $5 S, 8 \mathrm{aS})-5$-methyl-4,6,7,8,8a,9hexahydrothieno-[3,2-f] indolizinium iodide was prepared according to a standard protocol described in literature (Šafář et al., 2012). 


\section{Geometry}

All estimated standard deviations (esds) (except the esd in the dihedral angle between two l.s. planes) are estimated using the full covariance matrix. The cell esds are taken into account individually in the estimation of esds in distances, angles and torsion angles; correlations between esds in cell parameters are only used when they are defined by crystal symmetry.

\section{Refinement}

Refinement of $\mathrm{F}^{2}$ against all reflections. The weighted $R$-factor $w R$ and goodness of fit $\mathrm{S}$ are based on $\mathrm{F}^{2}$, conventional $R$-factors $R$ are based on $\mathrm{F}$, with $\mathrm{F}$ set to zero for negative $\mathrm{F}^{2}$. The threshold expression of $\mathrm{F}^{2}>2 \mathrm{~s}\left(\mathrm{~F}^{2}\right)$ is used only for calculating $R$-factors $(\mathrm{gt})$ etc. and is not relevant to the choice of reflections for refinement. $R$-factors based on F2 are statistically about twice as large as those based on $\mathrm{F}$, and R-factors based on all data will be even larger. All $\mathrm{H}$ atoms were positioned with idealized geometry using a constrained riding model with

$\mathrm{C}-\mathrm{H}$ distances in the range of $0.93-0.98 \AA$. The $U_{\text {iso }}(\mathrm{H})$ values were set at $1.2 U_{\text {eq }}(\mathrm{C}$-aromatic) or $1.5 U_{\text {eq }}(C$-methyl). An absolute structure was established using anomalous dispersion effects; Friedel pairs were not merged.

\section{Data collection}

Crystal data and conditions of data collection and refinement are reported in Tab. 1. CrysAlis CCD (Oxford Diffraction, 2009); cell refinement: CrysAlis RED (Oxford Diffraction, 2009); data reduction: CrysAlis RED (Oxford Diffraction, 2009); program(s) used to solve structure: SHELXS97 (Sheldrick, 2008); program(s) used to refine structure: SHELXL97 (Sheldrick, 2008); molecular graphics: DIAMOND (Brandenburg, 2001); software used to prepare material for publication: enCIFer (Allen et al., 2004) and PLATON (Spek, 2009), WinGX (Farrugia, 1999).

\section{Results and Discussion}

The absolute configuration is known from the synthesis and has been established without ambiguity from the anomalous dispersion of the I atom [absolute structure parameter -0.020 (16) (Flack, 1983)]. The molecular geometry and the atom numbering scheme of the title compound is shown in Fig. 2. The crystal packing of the title compound is shown in Fig. 3. The geometric parameters are in Tab. 2 and Tab. 3. The electron structure of the title compound was calculated by the semiempirical quantum chemistry method PM3, (Stewart, 2012). The net charges on the individual atoms and the values of Wiberg bond indices $I_{\mathrm{w}}$ (Wiberg, 1968)
Tab. 1. Experimental details.

\begin{tabular}{|c|c|}
\hline Empirical formula & $\mathrm{C}_{11} \mathrm{H}_{16} \mathrm{NS} \cdot \mathrm{I}$ \\
\hline Formula weight & $\mathrm{M}_{\mathrm{r}}=321.21$ \\
\hline Temperature & 298(2) K \\
\hline \multirow[t]{2}{*}{ Wavelength } & $\lambda=0.71073 \AA$ \\
\hline & Mo $\mathrm{K}_{\alpha}$ radiation, \\
\hline Crystal system, space group & Orthorhombic, $P 2_{1} 2_{1} 2_{1}$ \\
\hline \multirow[t]{3}{*}{ Unit cell dimensions } & $\mathrm{a}=6.5733(1) \AA$ \\
\hline & $\mathrm{b}=7.3104(1) \AA$ \\
\hline & $\mathrm{c}=25.8090(6) \AA$ \\
\hline Volume & $\mathrm{V}=1240.21(4) \AA^{3}$ \\
\hline Z, Calculated density & $4,1.720 \mathrm{Mg} / \mathrm{m}^{3}$ \\
\hline Crystal size & $0.45 \times 0.25 \times 0.20 \mathrm{~mm}$ \\
\hline Reflections collected/unique & $\begin{array}{l}19081 / 2181 ; 2141 \text { reflections } \\
\text { with } \mathrm{I}>2 \sigma(\mathrm{I})\end{array}$ \\
\hline Refinement method & $\begin{array}{l}\text { Full-matrix least-squares } \\
\text { on } \mathrm{F}^{2}\end{array}$ \\
\hline Data/restraints/parameters & $2181 / 0 / 127$ \\
\hline Goodness-of-fit on $\mathrm{F}^{2}$ & $\mathrm{~S}=1.03$ \\
\hline Absolute structure parameter & $-0.020(13)($ Flack, 1983) \\
\hline Final $R$ indices $[\mathrm{I}>2 \operatorname{sigma}(\mathrm{I})]$ & $\mathrm{R} 1=0.013, \mathrm{wR} 2=0.036$ \\
\hline Largest diff. peak and hole & 0.30 and -0.27 e. $\mathrm{A}^{-3}$ \\
\hline Monochromator & Graphite \\
\hline
\end{tabular}

Tab. 2. Selected geometric parameters: bond lengths $[\AA]$.

\begin{tabular}{llll}
\hline $\mathrm{C} 2-\mathrm{N} 1$ & $1.515(3)$ & $\mathrm{C} 8-\mathrm{C} 9$ & $1.343(4)$ \\
$\mathrm{C} 2-\mathrm{C} 3$ & $1.522(3)$ & $\mathrm{C} 9-\mathrm{C} 10$ & $1.427(3)$ \\
$\mathrm{C} 3-\mathrm{C} 4$ & $1.537(3)$ & $\mathrm{C} 7-\mathrm{S} 1$ & $1.721(2)$ \\
$\mathrm{C} 4-\mathrm{C} 5$ & $1.515(3)$ & $\mathrm{C} 8-\mathrm{S} 1$ & $1.718(3)$ \\
$\mathrm{C} 5-\mathrm{C} 6$ & $1.518(3)$ & $\mathrm{C} 10-\mathrm{C} 11$ & $1.496(3)$ \\
$\mathrm{C} 5-\mathrm{N} 1$ & $1.525(3)$ & $\mathrm{C} 11-\mathrm{N} 1$ & $1.497(3)$ \\
$\mathrm{C} 6-\mathrm{C} 7$ & $1.494(3)$ & $\mathrm{C} 12-\mathrm{N} 1$ & $1.504(3)$ \\
$\mathrm{C} 7-\mathrm{C} 10$ & $1.368(3)$ & & \\
\hline
\end{tabular}

Tab. 3. Selected geometric parameters: bond angles $\left[{ }^{\circ}\right]$.

\begin{tabular}{lllr}
\hline $\mathrm{N} 1-\mathrm{C} 2-\mathrm{C} 3$ & $103.7(2)$ & $\mathrm{C} 8-\mathrm{C} 9-\mathrm{C} 10$ & $113.1(2)$ \\
$\mathrm{C} 4-\mathrm{C} 5-\mathrm{N} 1$ & $103.4(2)$ & $\mathrm{C} 7-\mathrm{C} 10-\mathrm{C} 9$ & $112.0(2)$ \\
$\mathrm{C} 2-\mathrm{C} 3-\mathrm{C} 4$ & $105.8(2)$ & $\mathrm{C} 7-\mathrm{C} 10-\mathrm{C} 11$ & $122.6(2)$ \\
$\mathrm{C} 4-\mathrm{C} 5-\mathrm{C} 6$ & $118.9(2)$ & $\mathrm{C} 9-\mathrm{C} 10-\mathrm{C} 11$ & $125.4(2)$ \\
$\mathrm{C} 5-\mathrm{C} 4-\mathrm{C} 3$ & $105.4(2)$ & $\mathrm{C} 10-\mathrm{C} 11-\mathrm{N} 1$ & $109.4(2)$ \\
$\mathrm{C} 7-\mathrm{C} 6-\mathrm{C} 5$ & $109.2(2)$ & $\mathrm{C} 11-\mathrm{N} 1-\mathrm{C} 12$ & $109.2(2)$ \\
$\mathrm{C} 10-\mathrm{C} 7-\mathrm{C} 6$ & $124.4(2)$ & $\mathrm{C} 11-\mathrm{N} 1-\mathrm{C} 2$ & $113.5(2)$ \\
$\mathrm{C} 6-\mathrm{C} 5-\mathrm{N} 1$ & $110.4(2)$ & $\mathrm{C} 11-\mathrm{N} 1-\mathrm{C} 5$ & $110.7(2)$ \\
$\mathrm{C} 10-\mathrm{C} 7-\mathrm{S} 1$ & $111.4(2)$ & $\mathrm{C} 12-\mathrm{N} 1-\mathrm{C} 5$ & $112.6(2)$ \\
$\mathrm{C} 6-\mathrm{C} 7-\mathrm{S} 1$ & $124.1(2)$ & $\mathrm{C} 2-\mathrm{N} 1-\mathrm{C} 5$ & $101.5(2)$ \\
$\mathrm{C} 9-\mathrm{C} 8-\mathrm{S} 1$ & $111.9(2)$ & $\mathrm{C} 8-\mathrm{S} 1-\mathrm{C} 7$ & $91.6(1)$ \\
\hline
\end{tabular}

are given in Tab. 4. The CCDC deposit number is 863990. The expected stereochemistry of atoms $\mathrm{N} 1$ and C5 was confirmed as S, S. 
Tab. 4. Values of net charges at individual atoms and Wiberg bonding indices $I_{\mathrm{w}}$.

\begin{tabular}{llll}
\hline Atom & Charge, $q$ & Bond & $I_{\mathrm{w}}$ \\
\hline I1 & -0.994 & $\mathrm{~N} 1-\mathrm{C} 2$ & 0.957 \\
C2 & -0.149 & $\mathrm{C} 2-\mathrm{C} 3$ & 0.991 \\
C3 & -0.087 & $\mathrm{C} 3-\mathrm{C} 4$ & 0.983 \\
C4 & -0.082 & $\mathrm{C} 4-\mathrm{C} 5$ & 0.983 \\
$\mathrm{C} 5$ & -0.159 & $\mathrm{C} 5-\mathrm{C} 6$ & 0.979 \\
C6 & 0.026 & $\mathrm{C} 6-\mathrm{C} 7$ & 0.986 \\
C7 & -0.324 & $\mathrm{C} 7-\mathrm{C} 10$ & 1.610 \\
C8 & -0.239 & $\mathrm{C} 8-\mathrm{C} 9$ & 1.691 \\
C9 & -0.055 & $\mathrm{C} 9-\mathrm{C} 10$ & 1.200 \\
C10 & -0.135 & $\mathrm{C} 10-\mathrm{C} 11$ & 0.987 \\
C11 & -0.079 & $\mathrm{~N} 1-\mathrm{C} 11$ & 0.958 \\
C12 & -0.147 & $\mathrm{~N} 1-\mathrm{C} 12$ & 0.974 \\
N1 & 0.566 & $\mathrm{~N} 1-\mathrm{C} 5$ & 0.938 \\
S1 & 0.389 & $\mathrm{~S} 1-\mathrm{C} 7$ & 1.142 \\
& & $\mathrm{~S} 1-\mathrm{C} 8$ & 1.154 \\
\hline
\end{tabular}

Tab. 5. Hydrogen-bond geometry $\left(\AA{ }^{\circ}{ }^{\circ}\right.$.

\begin{tabular}{lcccc}
\hline $\mathrm{D}-\mathrm{H} \cdots \mathrm{A}$ & $\mathrm{D}-\mathrm{H}$ & $\mathrm{H} \cdots \mathrm{A}$ & $\mathrm{D} \cdots \mathrm{A}$ & $\mathrm{D}-\mathrm{H} \cdots \mathrm{A}$ \\
\hline $\mathrm{C} 11-\mathrm{H} 11 A \cdots \mathrm{I}^{\mathrm{i}}$ & $0.97(2)$ & $3.19(2)$ & $4.158(2)$ & $173.0(2)$ \\
$\mathrm{C} 12-\mathrm{H} 12 \mathrm{~B} \cdots \mathrm{I} 1^{\mathrm{ii}}$ & $0.96(2)$ & $3.00(2)$ & $3.930(2)$ & $162.5(3)$
\end{tabular}

Symmetry codes: (i) x, y, z; (ii) x, y - 1, z.

The central six-membered piperidine ring of the indolizine moiety and the pyrrolidine ring are not planar and adopt a half-chair and an envelope conformation with ring-puckering parameters (Cremer, Pople, 1975) calculated for the atom sequence N1-C5-C6-C7-C10-C11 of $\mathrm{Q}=0.515$ (2) A, $\theta=46.8(2)^{\circ}$ and $\varphi=267.0(4)^{\circ}$ for the piperidine ring and for the atom sequence N1-C2-C3-C4C5 of $Q=0.436$ (2) $\AA$ and $\varphi=357.4$ (3) for the pyrrolidine ring. A calculation of least-squares planes shows that these rings are puckered in such a manner that the five atoms N1, C6, C7, C10, C11 of the piperidine ring and the four atoms C2, C3, $\mathrm{C} 4$, C5 of the pyrrolidine ring are coplanar, while atom $\mathrm{C} 5$ is displaced by -0.686 (2) $\AA$ and atom N1 is displaced by 0.661 (2) $\AA$, respectively. On the other hand, the thiophene ring is essentially planar with a maximum deviation from the mean plane of the five ring atoms of 0.004 (3) $\AA$ for atom C8. The dihedral angles between the plane of the five atoms C6, C7, C10, C11 and $\mathrm{N} 1$ of piperidine ring and the plane of the thiophene ring is $12.8(1)^{\circ}$.
The crystal structure of the salt can be described as a donor-acceptor adduct, in which the independent components are connected through a hydrogenbonding network. A detailed examination of the molecular packing reveals that the cation and anion are connected alternately by means of two the intramolecular C11-H11 A ...I1 and the intermolecular C12-H12B …I1 hydrogen interactions as $\mathrm{H}$-atoms donor, link the molecules into infinite C(4) (Bernstein et al., 1995) zigzag chains along the b axis (Fig. 3 and Tab. 4) and help to stabilize the crystal structure.

Calculation of the electronic structure of a compound provides several indices which characterize the distribution of electron density in the molecule and the multiplicity of atomic bonds. The net charges give a picture of the distribution of electron density in the molecule and the values of the Wiberg bond indices enable one to estimate the

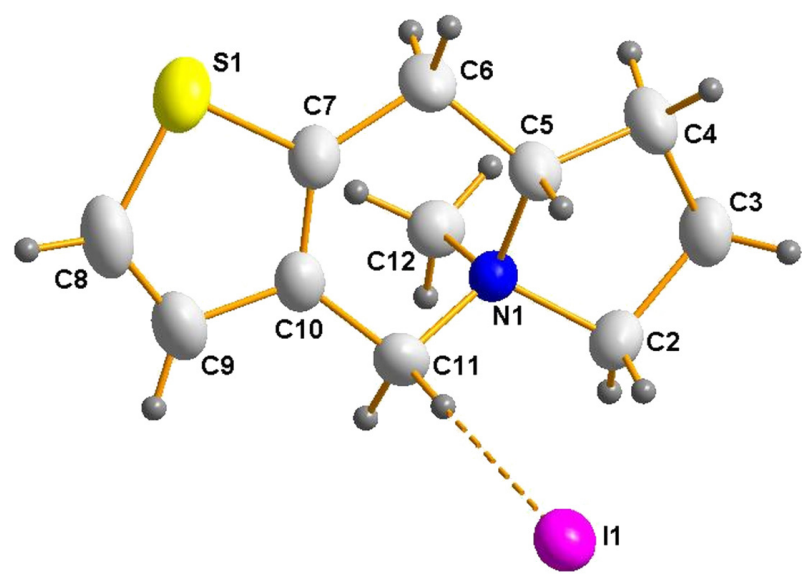

Fig. 2. Molecular structure of the title compound showing the atom labelling scheme. Displacement ellipsoids are drawn at the $50 \%$ probability level

(Brandenburg, 2001). The intramolecular hydrogen interaction is shown as a dashed line.

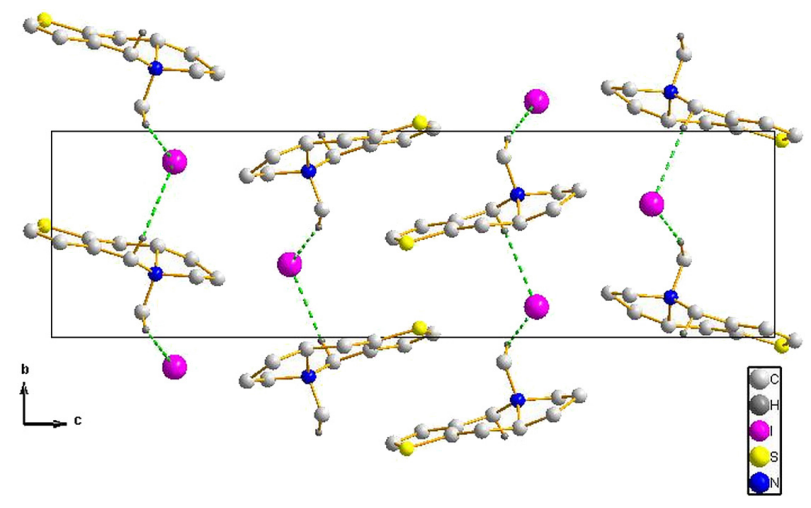

Fig. 3. Packing view of the title compound. Hydrogen interactions $\mathrm{C}-\mathrm{H} \cdots \mathrm{I}$ are shown by green dashed lines. $\mathrm{H}$ atoms not involved in hydrogen bonding have been omitted. 
multiplicity of individual atomic bonds. The net charge distribution in the molecule indicates that the large positive charges are localized at the atoms $\mathrm{N} 1$ (0.566) and S1 (0.389), whereas the negative net charge is located on atom I1 (-0.994). This charge distribution and the spatial arrangement (geometry) of the molecule govern its biological activity and are important for the overall stabilization of the crystal structure. It follows from the Wiberg index values for the bonds C7-C10 $\left(I_{\mathrm{w}}=1.610\right)$ and C8 - C9 $\left(I_{\mathrm{w}}=1.691\right)$ is not a pure double bond, but that $\pi$-electrons are delocalized in the region of the thiophene ring. The values of the Wiberg indices for the bonds S1-C7 $\left(I_{\mathrm{w}}=1.142\right)$ and S1-C8 $\left(I_{\mathrm{w}}=1.154\right)$, indicate the character of partial single or conjugated bonds. The other bonds of the central six-membered and pyrrolidine ring have the character of single bonds (Tab. 4.). The results of these calculations are in good agreement with the experimental values of the bond lengths found by the X-ray structure analyses.

\section{Acknowledgement}

This work was supported by the Slovak Research and Development Agency under the contract Nos. APVV0797-11 and APVV-0204-10. This contribution is also the result of the project: Research Center for Industrial Synthesis of Drugs, ITMS 26240220061, supported by the Research E Development Operational Programme funded by the ERDF. The authors thank the Structural Funds, Interreg IIIA, for financial support in purchasing the diffractometer.

\section{References}

Allen FH, Johnson O, Shields GP, Smith BR, Towler M (2004) J. Appl. Cryst. 37: 335-338.

Bernstein J, Davis RE, Shimoni L, Chang NL (1995). Angew. Chem. Int. Ed. Engl. 34: 1555-1573.

Brandenburg K. (2001). DIAMOND. Crystal Impact GbR, Bonn, Germany.
Butters TD (2002) Chem. Biol. 9: 1266-1268.

Clark RC, Reid JS (1995) Acta Cryst. A51: 887-897.

Compain P, Martin OR (2001) Bioorg. Med. Chem. 9: 3077-3092.

Couture A, Deniau E, Grandclaudon P, Leburn S, Leonce S, Renard P, Pfeiffer B (2000). Med. Chem. 8: 2113-2125.

Cremer D, Pople JA (1975) J. Am. Chem. Soc. 97: 1354-1362.

Farrugia LJ (1999) J. Appl. Cryst. 30: 565.

Flack HD (1983) Acta Cryst. A39: 876-881.

Foster C, Ritchie M, Selwood DI., Snowden W (1995) Antivir. Chem. Chemother. 6: 289-297.

Fujita T, Nagasawa H, Uto Y, Hashimoto T, Asakawa Y, Hori H (2004) Org. Lett. 6: 827-830.

Gerber-Lemaire, S. \& Juillerat-Jeanneret, L. (2006). Mini Rev. Med. Chem. 6, 1043-1052.

Gundersen LL, Negussie AH, Rise F, Ostby OB (2003) Arch. Pharm. (Weinheim) 336: 191-195.

Jorgensen AS, Jacobsen P, Chirstiansen L B, Bury PS, Kanstrup A, Thorp SM, Bain S, Naerum L, Wassermann K (2000) Bioorg. Med. Chem. Lett. 10: 399-402.

Lillelund VH, Jensen HH, Liang XF, Bols M (2002) Chem. Rev. 102: 515-554.

Melo EB, Gomes A, Carvalho I (2006) Tetrahedron 62: 10277-10302.

Michael JP (2003) Nat. Prod. Rep. 20: 458-475.

Oxford Diffraction (2009). CrysAlisPro. Oxford Diffraction Ltd, Abingdon, Oxfordshire, England.

Sheldrick GM (2008) Acta Cryst. A64: 112-122.

Shi GF, Li JQ, Jiang XP, Cheng Y (2008) Tetrahedron 64: 5005-5012.

Spek AL (2009) Acta Cryst. D65: 148-155.

Stewart JJP (2012) MOPAC2012-DG3. Stewart Computational Chemistry, Colorado Springs, CO, USA.

Šafář P, Žužiová J, Marchalín Š, Prónayová N, Švorc L, Vrábel V, Šesták S, Rendič D, Tognetti V, Joubert L, Daich A (2012) Eur. J. Org. Chem. 5498-5514.

Teklu S, Gundersen LL, Larsen T, Malterud KE, Rise F (2005) Bioorg. Med. Chem. 13: 3127-3139.

Wiberg KB (1968) Tetrahedron, 24(3): 1083-1096. 